\title{
Analysis on Development of Transverse - Sectioned Weld Zone using FEM Verified with Multipulsed Resistance Seam Welding
}

\author{
N Muhammad and YHP Manurang* \\ Faculty of Mechanical Engineering, Universiti Teknologi Mara, 40450 Shah Alam, Malaysia
}

Received 1 June 2011; accepted 2 March 2013

\begin{abstract}
Abstract: This paper details an investigation, through an experimental study, of the development of weld nuggets and a heat-affected zone (HAZ) in resistance seam welding (RSEW) using a numerical simulation approach. SYSWELD software for the simulation of heat treatment, welding, and welding assembly was utilized for the simulation process. The integrated Spot Weld Advisor (SWA) in SYSWELD was applied to simulate the RSEW model using a two-dimensional axis-symmetric FE model with customized electrode meshing. The thermal-mechanical-electrical characteristic and contact condition were taken into account throughout this study. The developed model comprised a transverse cross section for welding two layers of low carbon steel with a thickness of $1 \mathrm{~mm}$. For the experimental verification, three-pulsed RSEW with two different current stages was carried out. It was discovered that this program code, Spotweld Advisor, when used with the meshing method, was capable of offering results that were in agreement with physical experiments.
\end{abstract}

Keywords: Customized electrode meshing, Finite element method (FEM), Resistance seam welding, SWA SYSWELD, Visual-Mesh

$$
\begin{gathered}
\text { تحليل لتطوير نموذج بطريقة العنصر المُدود لدراسة نطاق لحام مستقطع عرضيا تم التحقق منه من خلال اللحام باستخدام المقاومة متعددة النبضة } \\
\text { نوراسياه محمد و يوبتير هارانجان براسادا مانورينج" }
\end{gathered}
$$

الملخص: تهدف هذه الورقة إلى عرض تفاصيل دراسية بحثية أجريت خلال دراسة تجريبية حول تكون كتل لحام صلبة ونطاق متضرر حراريا

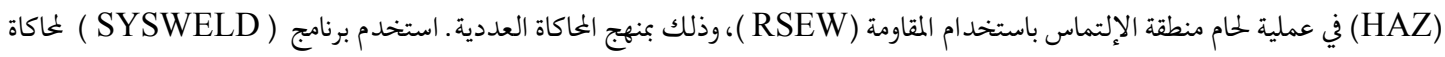

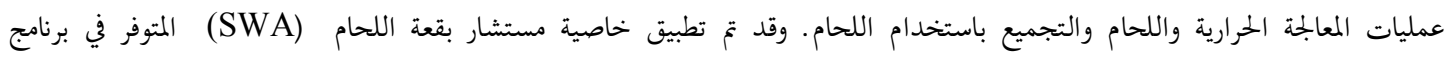

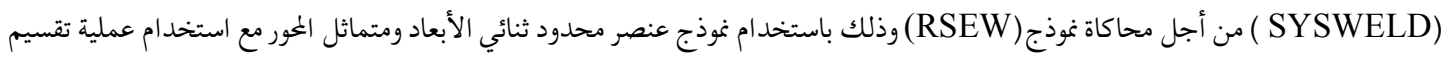

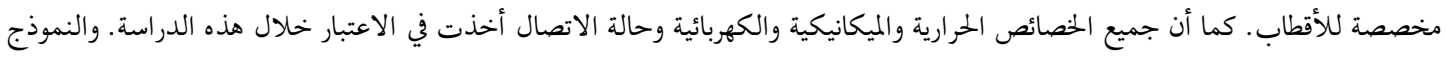

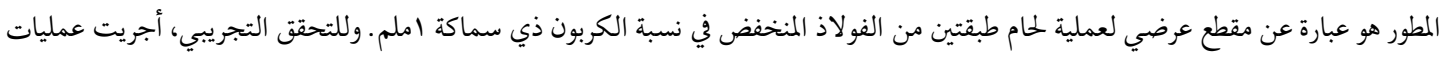

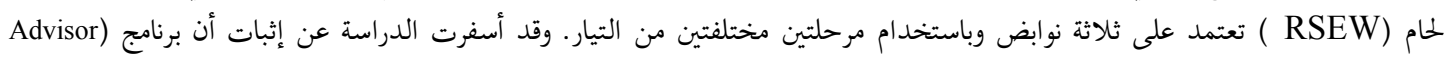
(Spotweld المفردات المفتاحية: خاصية تقسيم القطب، طريقة العنصر المحدود، لحام الالتماس بالمقاومة، تقسيم مرئي

\footnotetext{
*Corresponding author's e-mail: amtex.uitm@gmail.com
} 


\section{Introduction}

Resistance seam welding (RSEW) is widely employed for the fabrication of automotive gas tanks which require water or air tightness. Highly reliable welding procedures which produce a high quality result are required, as leakage within the system renders the tank unsafe. In general, the quality of the weld is strongly dependent on the maintenance of the RSEW machine and the selection of optimum welding conditions (Manurung et al. 2010; Murakawa and Minami 2002 and Murakawa 2003). RSEW was originally a modification of resistance spot welding (RSW), which produces a continuity of overlapping spot welds by means of rotating wheel electrodes. This method forms a continuous, leak-tight joint.

In order to obtain a good quality weld nugget, many experiments have to be conducted which can require significant cost and time. One effective solution to this problem is to use a computer simulation (Zhang 2003; Eisazadeh et al. 2010; Srikunwong et al. 2002). In our study, a finite element method (FEM) for seam welding was developed, and appropriate conditions were studied throughout the simulation process.

There are two possible two-dimensional (2-D) models of electrode geometries for seam welding- longitudinal cross section and transverse cross section (Murakawa and Minami 2002). In this research, only the transverse section of electrode geometries and sheet metal were developed using customized electrode meshing with mesh generator software VisualMesh 5.2 (ESI Group, Paris, France) followed by exporting the generated mesh into SYSWELD (ESI Group, Paris, France) for the numerical simulation of seam welding. Since there is no specific software to replicate the seam welding process, the integrated Spot Welding Advisor (SWA) in SYSWELD 2009 was utilized. Within this tool, all common parameters are readily available for spot welding and can be manipulated using customized meshing methods to simulate seam welding.

\section{Basic Principle of RSEW}

\subsection{Governing Equation and Boundary Condi- tions}

The general principle of RSEW is the Joule heating law (Song et al. 2005) where the heat, Q, is generated depending on three basic factors as expressed in the following formula:

$$
Q=I^{2} R t
$$

where $I$ is the current passing through the metal combination, $R$ is the resistance of the base metals and the contact interface, and $t$ is the time of the current flow. Force is applied before, during, and after the application of electric current to maintain the electrical connectivity and to provide the pressure necessary to produce defect-free seam welds. This process involves strong interactions between electrical, thermal, metallurgical, and mechanical fields (Feng et al. 1998; Feulvarch et al. 2004; Hou et al. 2007).

RSEW shares a similar principle regarding spot welding with different electrode geometry. Two rotating disc electrode wheels are used to apply current and force, with the discs rotating either continuously or intermittently. The seam welding electrode is expected to be similar to spot welding as can be seen from the side view (Fig. 1). In this investigation, a flat electrode wheel tip was used in which the contact radii were considered constant.

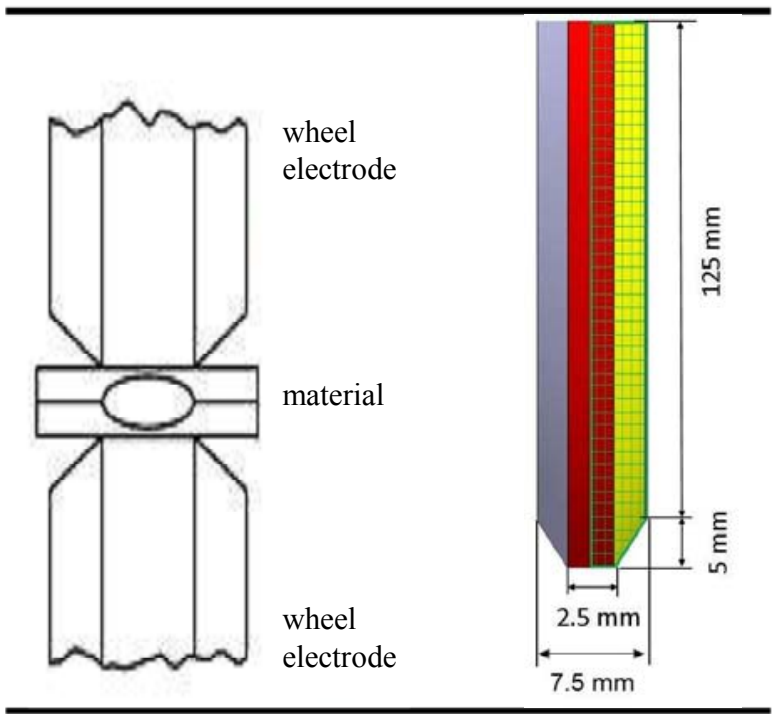

Figure 1. Transverse sectioned scam electrode and weld

According to the axis-symmetry and 2-D problems with full coupling between the electrical and thermal phenomena, the coupling system governing equations are as follows (Srikunwung et al. 2002):

$$
\begin{aligned}
& \rho \frac{\partial H}{\partial t}-\operatorname{div}(\lambda . \operatorname{grad} T)-\operatorname{grad} V \cdot \sigma \cdot \operatorname{grad} V-Q=0 \\
& \operatorname{div}(\sigma \cdot \operatorname{grad} V)=0
\end{aligned}
$$

where $\mathrm{T}$ and $\mathrm{V}$ are the temperature and the scalar electrical potential respectively. $\rho, \lambda$ and $\sigma$ represent the density, the thermal conductivity and the electrical conductivity of the media with respect to temperature dependency characteristic. $\mathrm{H}$ is the enthalpy with 
temperature dependency and Q is internal heat generation. The current flow in an electrical conductance generates Joule heating effect. The internal heat dissipation is represented in term of gradV.б.gradV.

Since a $50 \mathrm{~Hz}$ sine wave ac current was used, the welding current can be described with standard sinusoidal signal. Therefore, the root-mean square value of the welding current can be given by (Li et al. 2007).

$$
I_{r m s}=\sqrt{\frac{1}{\pi}} \int_{0}^{\pi}\left(I_{m} \sin 2 \pi f t\right)^{2} d(2 \pi f t)=\frac{I_{m}}{\sqrt{2}}
$$

where $I_{m}$ is the peak value, $I$ is the real current, and $f$ is the working frequency. Based on Eq. (4), the peak value of the welding current is $I_{m}=\sqrt{2} I_{r m s}$. As a result, the applied welding current on the upper end surface of the upper electrode can be given by:

$$
I=I_{m} \sin (2 \pi f t)=\sqrt{2} I_{r m s} \sin (2 \pi f t)
$$

In this simulation, a three-pulsed current was applied consisting of 1 cycle for the first, 3 cycles for the second, and 1 cycle for the third current stages (Fig. 2). In general, multi-pulsed current is applied when either too thick or too thin a base material is to be welded. Using multi-pulsed technology, the current needs a certain amount of cooling time in order to avoid the occurrence of an oxide layer (Cuff 1998).

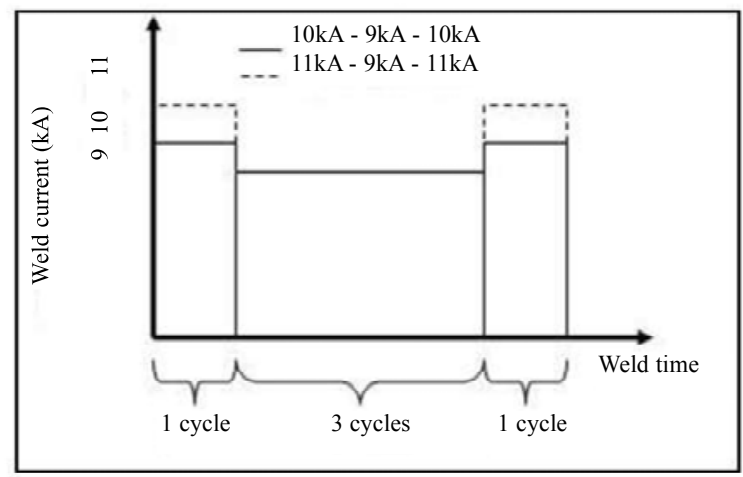

Figure 2. Schematic illustration of multipulsed weld current

The materials used in this research were low carbon steel with a thickness of $1.0 \mathrm{~mm}$ and electrodes made of copper alloy. Table 1 shows the material composition obtained from the data base of the FEM software, international standards, and an investigation using a spark emission spectrometer.

\subsection{Electrothermal Contact Conditions}

One of the most important considerations in modeling RSEW is the contact condition at the electrodesheet and sheet-sheet interfaces (Murukawa and Minami 2002). Under the application of the electrode force, the contact element becomes in contact. When it
Table 1. Material composition of low carbon steel

\begin{tabular}{cccc}
\hline & SYSWELD & $\begin{array}{c}\text { EN10025/ DIN } \\
\mathbf{1 7 1 0 0}\end{array}$ & $\begin{array}{c}\text { Experi- } \\
\text { ment }\end{array}$ \\
\hline$\% \mathrm{C}$ & 0.18 & $\max .0 .200$ & 0.186 \\
$\% \mathrm{Mn}$ & 1.60 & $\max .1 .600$ & 0.146 \\
$\% \mathrm{Si}$ & 0.55 & $\max .0 .550$ & 0.011 \\
$\% \mathrm{~S}$ & 0.035 & $\max .0 .035$ & 0.001 \\
$\% \mathrm{P}$ & 0.035 & $\max .0 .035$ & 0.001 \\
$\% \mathrm{Cr}$ & 0 & - & 0.035 \\
$\% \mathrm{Ni}$ & 0 & - & 0.032 \\
\hline
\end{tabular}

is in contact, enough stiffness is given to the contact element and the same values of the electric and thermal conductivity of the bulk materials are given to the contact element. The contact resistance is a function of contact pressure (Feng et al. 1998). As pressure increases, the resistance reduces and the heat generation across the object boundary is also reduced (Chigurupati et al. 2010).

The electrical and thermal contact resistance of the electrodes and the sheets are temperature dependent. SYSWELD 2009 defines the function of contact resistances with respect to temperature, using Fortran. In this simulation study, the thermal and electrical contact resistance between electrode-sheet and sheet-sheet was considered a weak coupling. In the weak coupling option, the thermal analysis was performed during the current application, followed by mechanical analysis at the end of the current application.

\section{Simulation Procedure and Experimental Set-up}

\subsection{SYSWELD's Customized Meshing Strategy}

SYSWELD in SWA offers two different methods for solving the RSW problem: a predefined method and a customized meshing method.

In the predefined method, a standard electrode form is selected and SYSWELD generates the meshing automatically after parameters such as curvature, radius of the electrode, internal radius, external radius, and height of the electrode are defined. While using the customized electrode meshing, electrode skins and geometry must be defined first and subsequently meshed according to the actual dimensions. In this research, the later meshing method was used to simulate seam welding created using Visual-Mesh, Version 5.2 as shown (ESI Group, Paris, France) (Fig. 3). The characteristics and functions of the curves are summarized as follows (Manurung et al. 2010). 


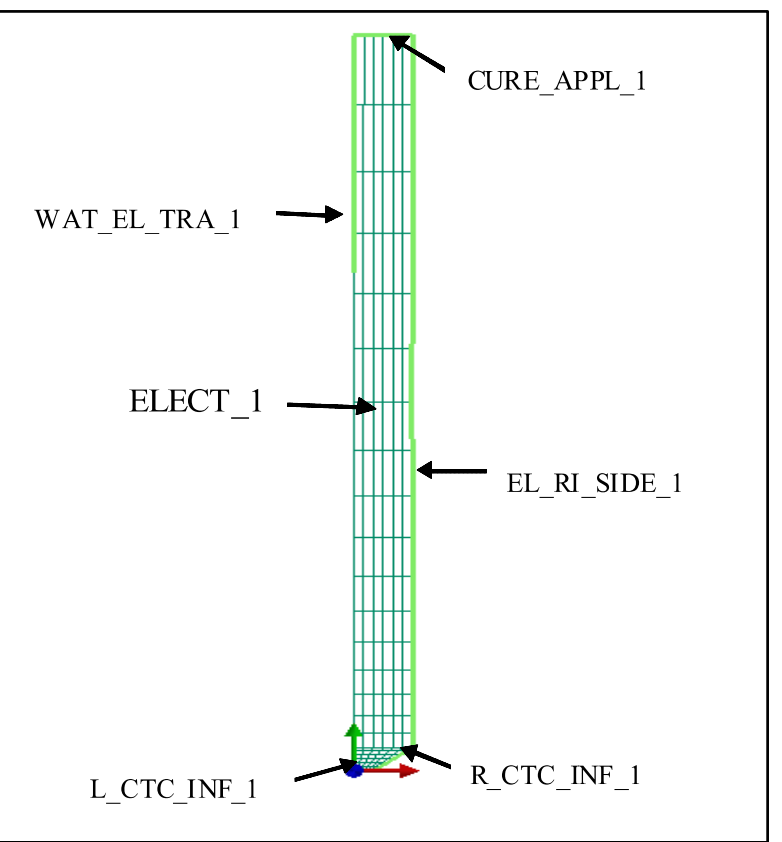

Figure 3. Meshing strategy of electrode and group definition of skin elements

Table 2. Simulation and experimental process parameters

\begin{tabular}{|c|c|c|c|c|c|}
\hline \multirow[b]{2}{*}{$\begin{array}{l}\text { Electrode } \\
\text { geometry }\end{array}$} & \multicolumn{4}{|c|}{ Parameter (s) } & \multirow[b]{2}{*}{$\begin{array}{l}\text { Welding } \\
\text { time } \\
\text { (cycle) }\end{array}$} \\
\hline & $\begin{array}{l}\text { Multipulsed weld current } \\
\text { (kA) }\end{array}$ & $\begin{array}{c}\text { Electrode } \\
\text { width/thic kn ess } \\
(\mathrm{mm})\end{array}$ & $\begin{array}{l}\text { Weld force } \\
\text { (N) }\end{array}$ & $\begin{array}{l}\text { Squeezing } \\
\text { time } \\
\text { (cycle) }\end{array}$ & \\
\hline \multirow{3}{*}{$\begin{array}{l}\text { Transverse } \\
\text { section }\end{array}$} & $10 \mathrm{kA}-9 \mathrm{kA}-10 \mathrm{kA}$ & \multirow{3}{*}{2.5} & \multirow{3}{*}{1,800} & \multirow{3}{*}{25} & \multirow{3}{*}{5} \\
\hline & & & & & \\
\hline & $11 \mathrm{kA}-9 \mathrm{kA}-11 \mathrm{kA}$ & & & & \\
\hline
\end{tabular}

i. WAT_EL_TRA_1 contains elements where thermal transfer between electrodes and water is modeled.

ii. CURE_APPL_1 contains elements where current density and pressure are applied.

iii. EL_RI_SIDE_1 contains elements where thermal transfer between electrodes and air is modeled.

iv. R_CTC_INF_1 contains elements where thermal transfer between electrodes and air is modeled, with additional sliding contact elements between electrodes and sheets.

v. L_CTC_INF_1 contains elements where thermal transfer between electrodes and sheets is modeled, with additional sliding or sticking (depending on the pressure application) contact elements between electrodes and sheets as well.

vi. ELECT_1 contains 2-D elements where electrothermo-metallurgical and mechanical properties are affected.

\subsection{Experimental Setup}

In this study, electrode size, material thickness, weld force, squeezing cycle, and weld cycle of the simulation and the experimental study were set to be constant throughout the investigation. The variable parameter was the applied three-pulse weld current, which was 10-9-10 kA and 11-9-11 kA. The details of the welding parameters are shown in Table 2. The experimental investigation on RSEW was conducted using NASH 10-100 (Fig. 4).

To measure the width and height of the weld nugget, and the heat-affected zone (HAZ), the welded metal was cut transversely from the middle position using a common cutting machine. In order to assure the precision of the specimen dimension, it was etched using a $2 \%$ Nital solution. The macrograph of the weld zone was captured using a metallurgical microscope interfaced with an image analysis system.

The development of the weld nugget and HAZ using the FEM simulation approach is represented in Figs. 5 and 6 , respectively. In the simulation for 5 weld cycles, a three-pulsed weld current of 10-9-10 kA and 11-9-11 kA were applied in which the first, second, and third pulses were 1 cycle, 3 cycles and 1 cycle for respective current stages. 


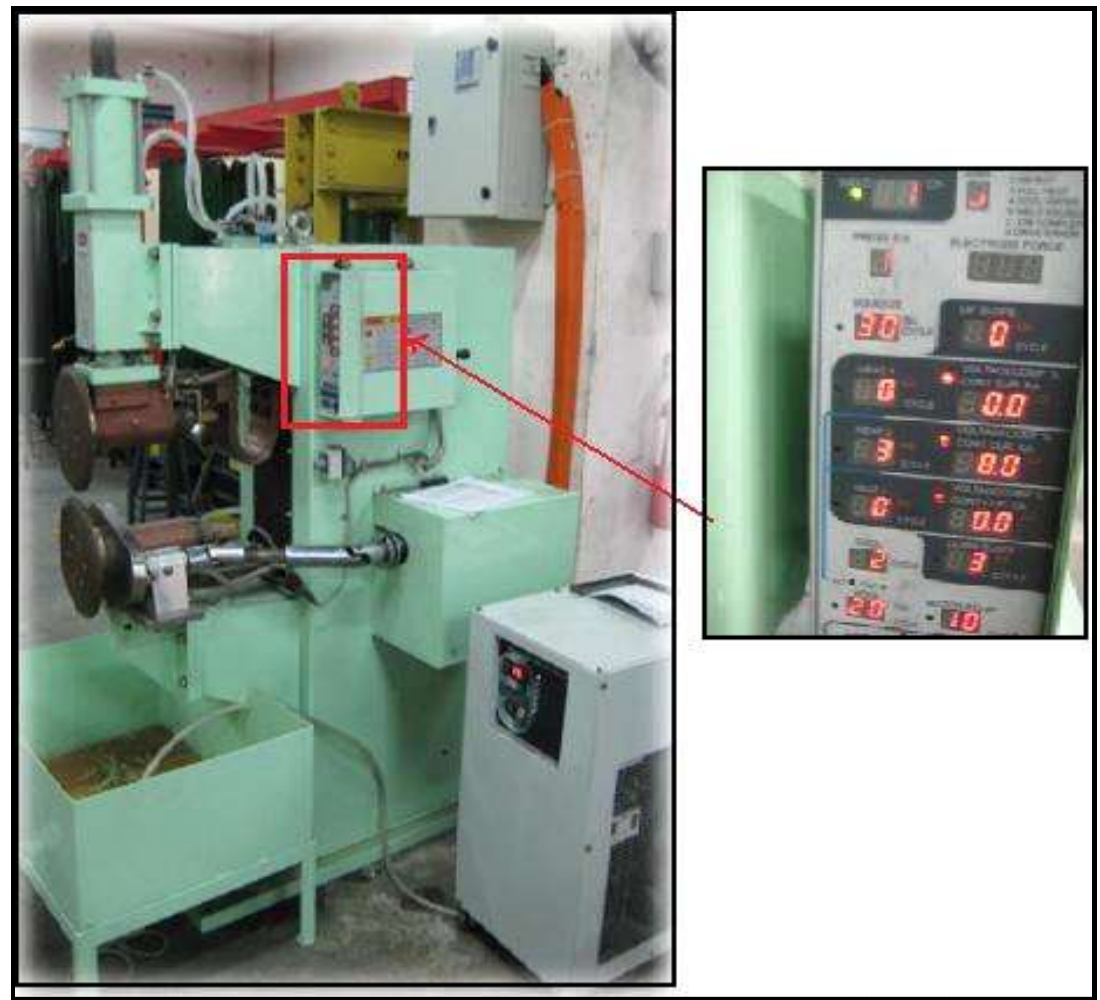

Figure 4. RSEW machine (Brand: NASH, type: 10-100)

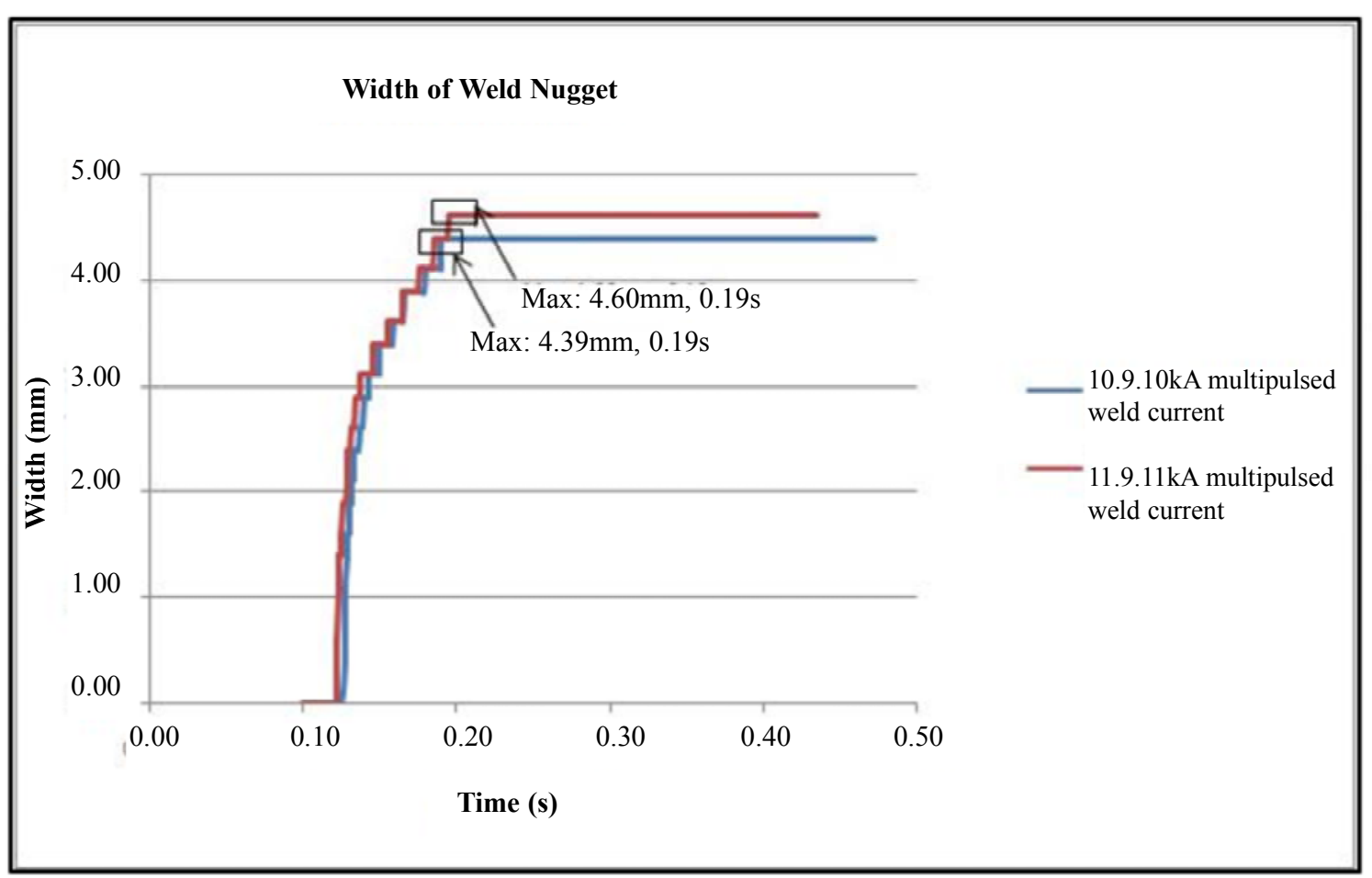

Figure 5. Graph for development of weld nugget

\section{Results and Discussions}

Figure 5 shows that, for the multi-pulsed weld current of 10-9-10 kA, the nugget width development started at 0.13 seconds, reaching the maximum value of $4.40 \mathrm{~mm}$ at 0.19 seconds, while for $11-9-11 \mathrm{kA}$, it started earlier ( 0.12 seconds) and reached the maximum value of $4.60 \mathrm{~mm}$ at 0.19 seconds. The final nugget was formed at the end of the hold time because there was some deformation in the welding zone when the well-meant cooled due to the electrode pressure and material shrinkage. 
N Muhammad and YHP Manurang

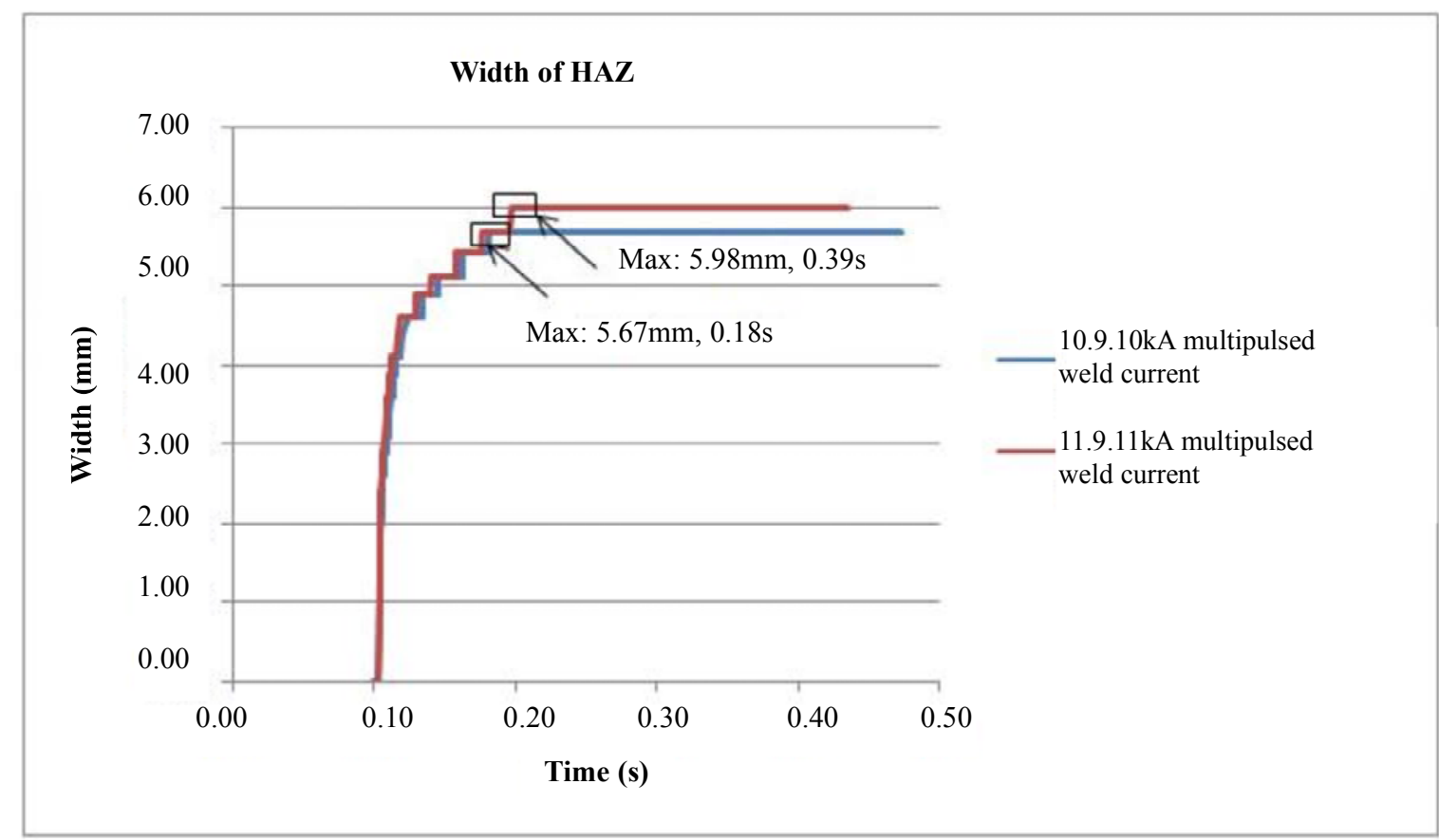

Figure 6. Graph for development of HAZ

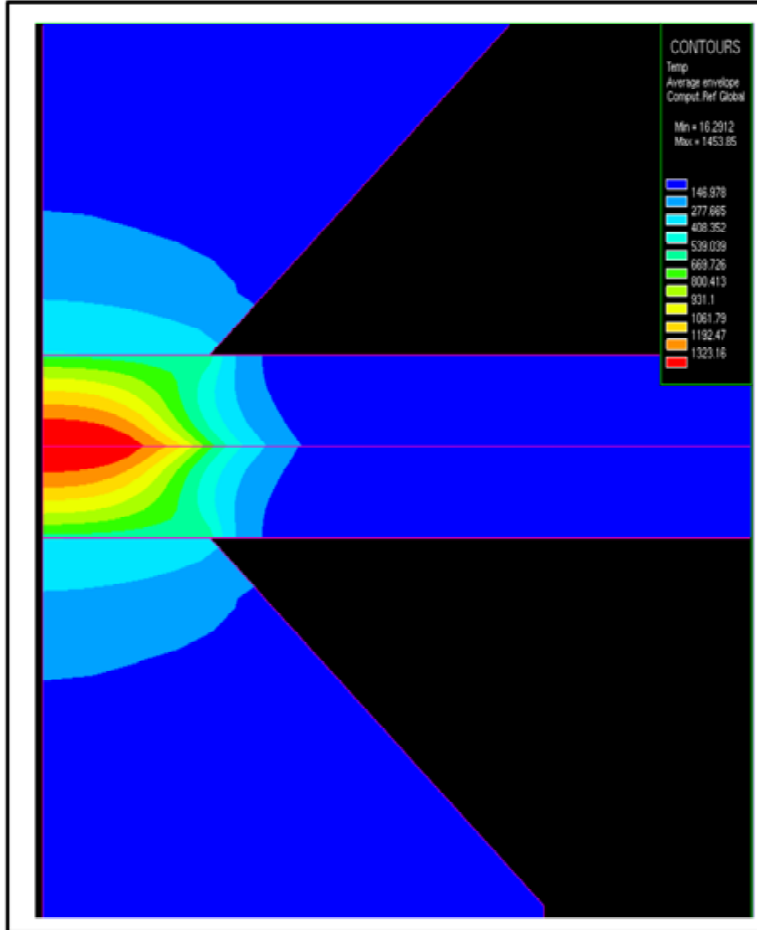

(a)

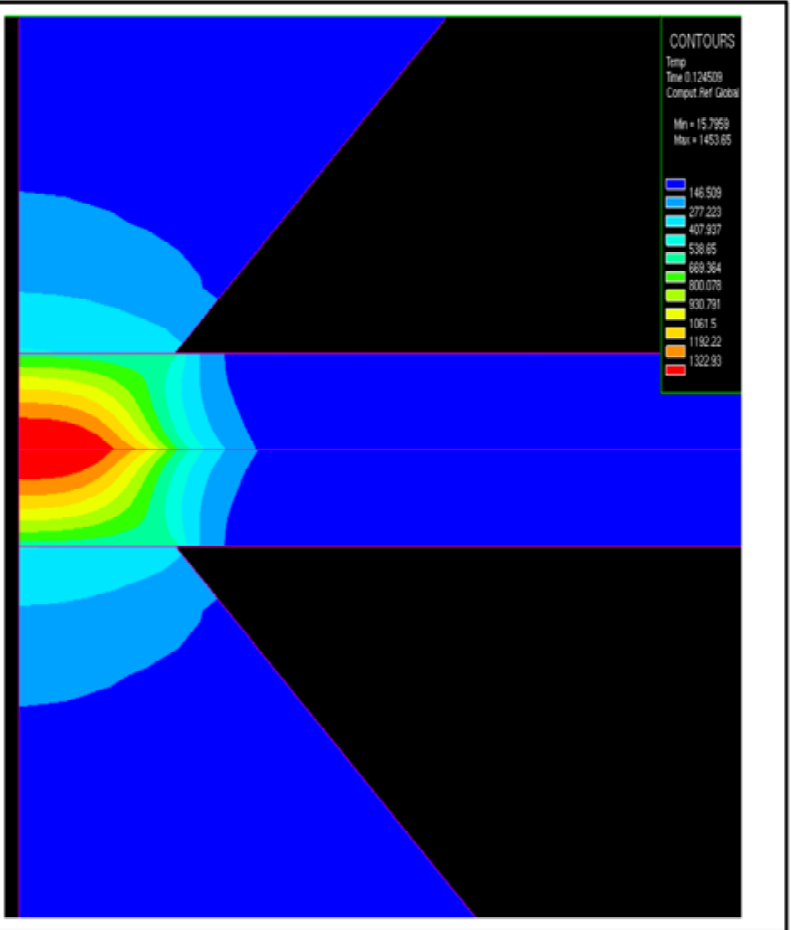

(b)

Figure 7. Temperature distribution at the time nugget started to form: (a) 10-9-10 kA weld current and (b) 11-9-11 kA weld current

Figure 5 also shows that the nugget size increased with the weld current. After applying the weld current, the temperature of the work pieces rose by the generation of Joule heat. In the Joule heating formula, heat generation due to electrical current is more considerable compared with heat due to time or force parameters. Therefore, a higher weld current generated more heat and formed a bigger weld nugget.
Figure 6 shows the development of HAZ. As the width of the weld nugget increased, the width of the $\mathrm{HAZ}$ also increased in proportion to the weld current.

Figure 7 shows the simulated temperature profile and nugget growth at the time when the nugget started to form. At the start of the welding process, the temperature at the center of faying surface increased very quickly. The highest temperature was always at the 


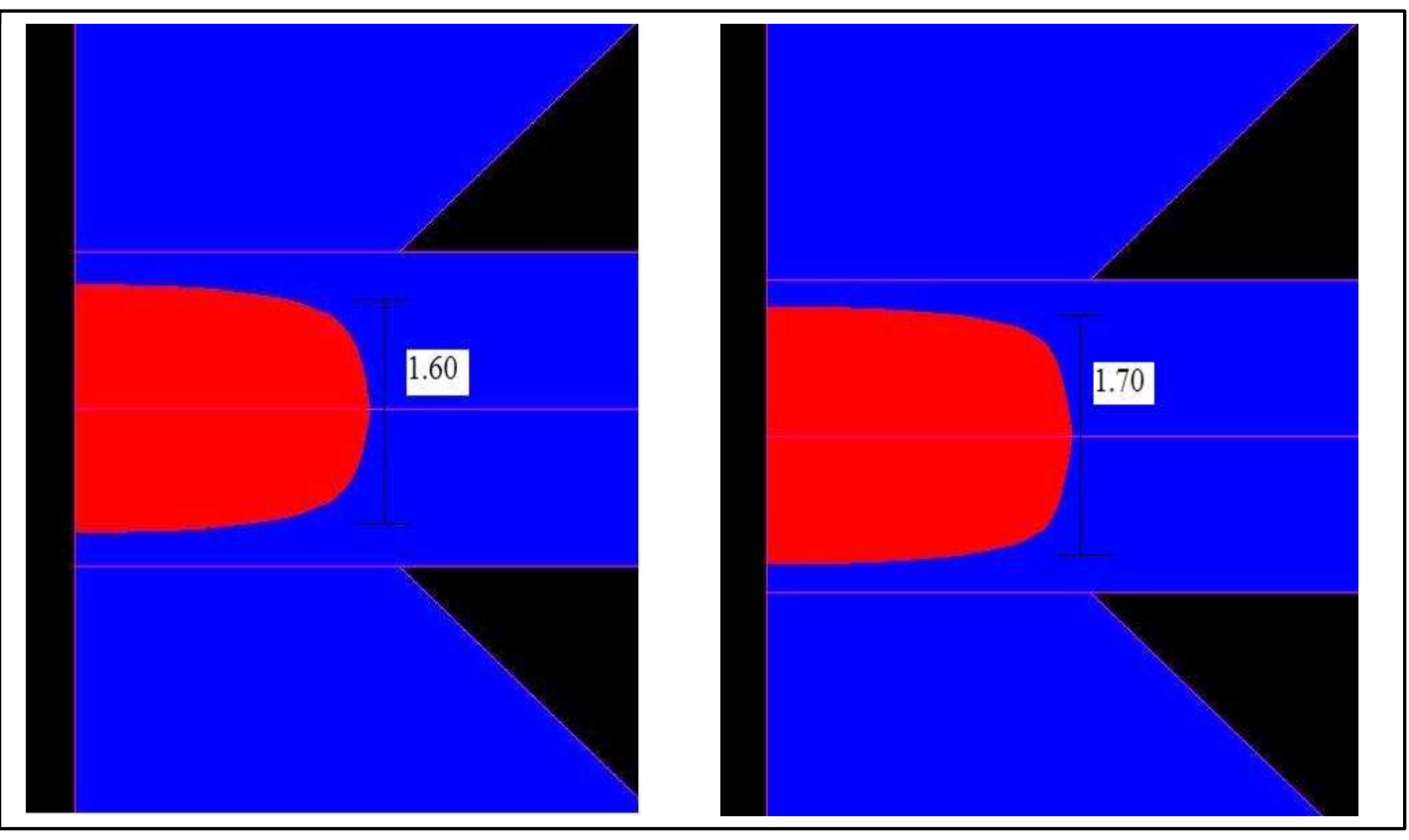

(a)

(b)

Figure 8. Simulation result of nugget development: (a) 10-9-10 kA weld current (b) 11-0-11 kA weld current

Table 3. Simulation and experimental results

\begin{tabular}{|c|c|c|c|c|c|c|c|}
\hline \multirow[b]{2}{*}{$\begin{array}{l}\text { Electrode } \\
\text { geometry }\end{array}$} & \multirow[b]{2}{*}{$\begin{array}{l}\text { Multipulsed weld } \\
\text { current (kA) }\end{array}$} & \multicolumn{3}{|c|}{ Simulation results } & \multicolumn{3}{|c|}{ Experimental result } \\
\hline & & $\begin{array}{c}\text { Width of } \\
\text { w eld } \\
\text { nugget } \\
\text { (m m) }\end{array}$ & $\begin{array}{c}\text { Width } \\
\text { of HA Z } \\
\text { (mm) }\end{array}$ & $\begin{array}{l}\text { Height of } \\
\text { w eld } \\
\text { nugget } \\
\text { (mm) }\end{array}$ & $\begin{array}{c}\text { Width of } \\
\text { w eld } \\
\text { nugget } \\
\text { (m m) }\end{array}$ & $\begin{array}{c}\text { Width } \\
\text { of HA Z } \\
(\mathrm{mm})\end{array}$ & $\begin{array}{c}\text { Height } \\
\text { of weld } \\
\text { nugget } \\
(\mathrm{mm})\end{array}$ \\
\hline \multirow{2}{*}{$\begin{array}{l}\text { Transverse } \\
\text { section }\end{array}$} & $10 \mathrm{kA}-9 \mathrm{kA}-10 \mathrm{kA}$ & 4.39 & 5.66 & 1.60 & 4.36 & 5.52 & 1.52 \\
\hline & $11 \mathrm{kA}-9 \mathrm{kA}-11 \mathrm{kA}$ & 4.60 & 5.98 & 1.70 & 4.59 & 5.90 & 1.60 \\
\hline
\end{tabular}

center of faying surface during the whole welding process. The nugget was shaped as a very flat ellipse. Melting occurred first at the faying surface and then expanded to the surrounded material. As the temperature rose, the nugget kept growing. When the electrical current was switched off, the well-meant started to cool down so the temperatures of the nugget decreased quickly due to the loss of heat by convection of the air and cooling water.

Figure 8 shows the simulation result of the nugget height development, which reached $1.60 \mathrm{~mm}$ for 10-9$10 \mathrm{kA}$ and increased to $1.70 \mathrm{~mm}$ for $11-9-11 \mathrm{kA}$. Results from the simulations showed good comparison with the experiments (Fig. 9).

The experimental investigation results are presented in the form of macrographs as shown in Fig. 9. From the macrographs, the width and height of the weld nugget and the HAZ were measured. The results obtained by simulation and experimentally are summarized in Table 3. The results indicate that the width of the weld nugget, and the HAZ itself is proportional to the increasing welding current, in both simulations and the experimental process with the RSEW. According to Hamedi and Pashazadeh, at a constant welding time, an increase of welding current affects the rise in nugget temperature (Hamedi and Pashazadeh 2008). Welding current is the most dominant factor that affects the nugget area, such that increasing the welding current simultaneously increases the nugget area (Darwish and Al-Dekhial 1999).

\section{Conclusions}

A simulation using customized electrode meshing, SYSWELD's SWA, and experimental process of RSEW on two sheet layers of low carbon steel with similar thicknesses was studied. It was discovered that a 2-D axis-symmetrical FEM could be developed using this meshing method to model the thermomechanical-electrical coupling of the RSEW for a transverse cross section of electrode geometry and material. It shows that the seam welding process can be simulated using SWA in SYSWELD. This tool was used throughout this research in order to investigate 


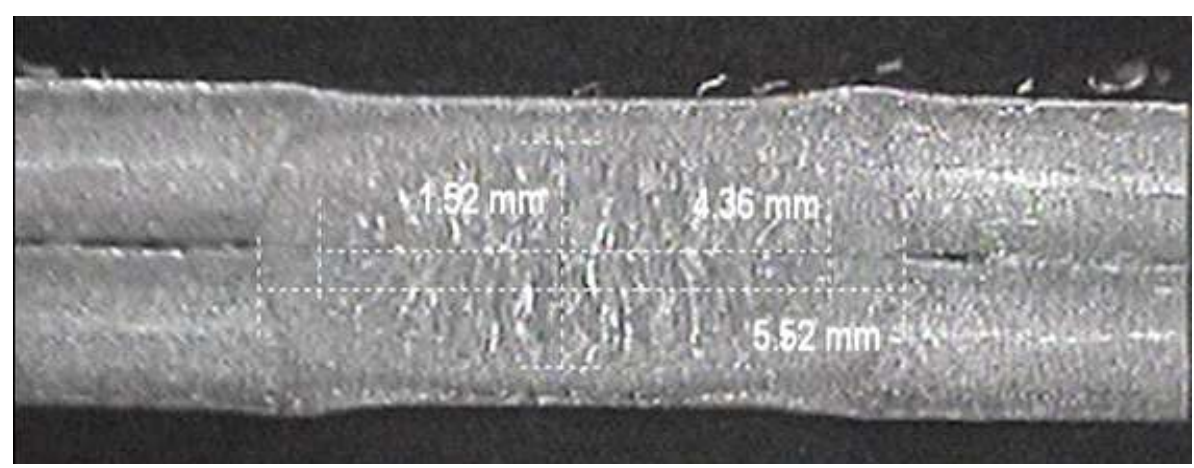

(a)

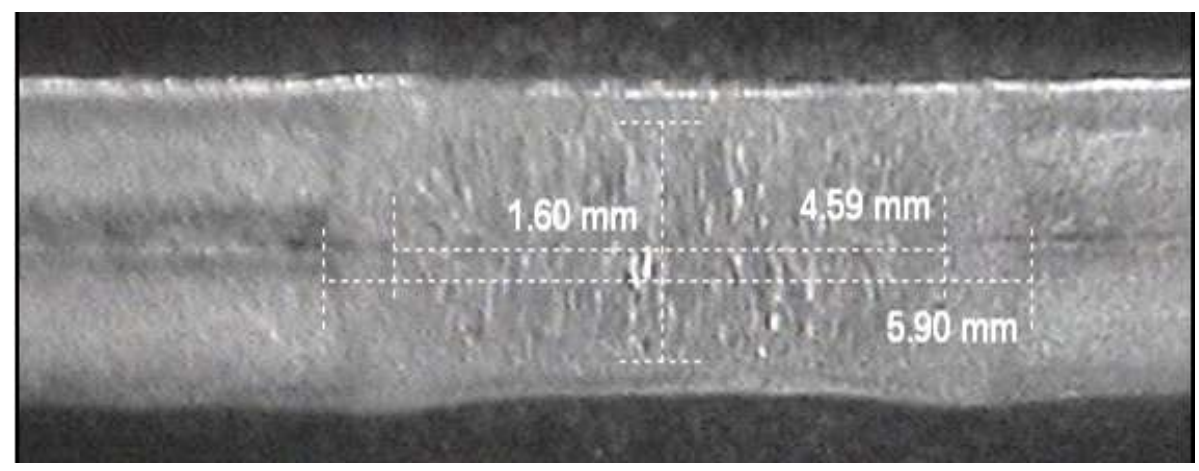

(b)

Figure 9. The etched macrographs with $2 \%$ Nital for multipulsed weld current: (a) 10-9-10 kA and (b) 11-9-11 $\mathrm{kA}$

the effect of various parameters on the formation of transverse-sectioned weld nugget.

From this study, it can be concluded that FEM simulation using SYSWELD'S SWA presents good agreement with experimental result in terms of the width and height of the weld nugget and HAZ. Furthermore, the information on the temperature and time profile was also available. The FEM simulation approach of the RSEW provides a better understanding of the effects of welding parameters on the nugget formation. It provides a precise analysis, and saves both cost and time over the welding process. It is well known that the rate of weld nugget growth is mostly influenced by welding current.

It is recommended that this study be continued further with other parameters such as materials, number of layers, sheet thicknesses, weld time, squeezing time, and electrode force. It is also recommended that various types of electrode meshing be investigated to determine their effect on nugget development and formation. Furthermore, the experimental investigation should be enhanced by using optical technology to measure the real-time development of the weld zone.

\section{Acknowledgments}

The authors would like to express their gratitude to the Faculty of Mechanical Engineering and the Advance Manufacturing Technology Excellence Centre (AMTEX) at the Universiti Technologi Mara (UiTM) in Shah Alam, Malaysia, for the facilities and technical support. A special thank you is addressed to the Malaysian Ministry of Higher Education (MOHE) for their financial support.

\section{References}

Chigurupati P, Chun BK, Bandar A, Wu WT (2010, Finite element modeling of resistance spot welding process. International J. Mater Form 3:991994.

Cuff R (1998), Using multiple-impulse (pulsation) resistance welding for coated material, The Fabricator 36-39.

Darwish SM, Al-Dekhial SD (1999), Statistical models for spot welding of commercial aluminum sheets. International J. Machine Tools Manufacturing 39:1589-1610.

Eisazadeh H, Hamedi M, Halvaee A. 2010. New parametric study of nugget size in resistance spot welding using finite element method. J. of Material and Design 31:149-157.

Feng Z, Babu SS, Santella ML, Riemer BW, Gould JE (1998), An incrementally coupled electrical-ther 
mal-mechanical model for resistance spot welding. 5th International Conference on Trends in Welding Research, Pine Mountain, GA.

Feulvarch E, Robin V, Bergheau JM (2004), Resistance spot welding simulation: a general finite element formulation of electrothermal contacts conditions, J. of Materials Processing Technology 153-154:436-441.

Hamedi M, Pashazadeh H (2008), Numerical study of nugget formation in resistance spot welding. International J. Mechanics 2:11-15.

Hou Z, Kim IS, Wang Y, Li C, Chen C (2007), Finite element analysis for the mechanical features of resistance spot welding process. J. of Material processing Technology 185:160-165.

Li YB, Lin ZQ, Hu SJ, Chen GL (2007), Numerical analysis of magnetic fluid dynamics behaviors during resistance spot welding. J. of Applied Physics 101.

Manurung YHP, Muhammad N, Haruman E, Abas SK, Tham G, Salleh KM, Chau CY (2010), Investigation on weld nugget and HAZ development of resistance spot welding using SYSWELD's customized electrode meshing and experimental verification. Asian J. of Industrial Engineering 2:63-71.
Murakawa H, Minami H (2002), Development of finite element method for seam welding and its application to optimization of welding condition. Proceedings of the Twelfth International Offshore and Polar Engineering Conference, Kitakyushu, Japan 344-347.

Murakawa H, Minami H, Kato T (2003), Finite element simulation of seam welding process, Trans. JWRI 30:111-117.

Murakawa H (2003), Simulation of resistance welding for selection of optimum welding conditions and process control. Trans. JWRI 32:215-218.

Song Q, Zhang W, Bay N (2005), An experimental study determines the electrical contact resistance in resistance welding. Welding Journal 73-76.

Srikunwong C, Dupuy T, Bienvenu Y (2002), A numerical and experimental study in resistance spot welding process, Ecole des Mines de Paris, France.

Zhang W (2003), Design and implementation of software for resistance welding process simulations. Society of Automotive Engineers, Inc. 105-113. 